\title{
Análise multicritério da ecoeficiência do transporte de cargas com veículos leves
}

\section{Rodrigo Goyannes Gusmão Caiado ${ }^{1}$, Victor Gomes Simão ${ }^{2}$, Luís Alberto Duncan Rangel ${ }^{3}$, Osvaldo Luiz Gonçalves Quelhas ${ }^{4}$, Gilson Brito Alves Lima ${ }^{5}$}

\author{
1Universidade Federal Fluminense, rodrigo.caiado@id.uff.br \\ 2Universidade Federal Fluminense, victorsimao@yahoo.com.br \\ 3Universidade Federal Fluminense, duncan@metal.eeimvr.uff.br \\ 4Universidade Federal Fluminense, quelhas@latec.uff.br \\ ${ }^{5}$ Universidade Federal Fluminense, glima@id.uff.br
}

\section{Recebido:}

31 de janeiro de 2017

Aceito para publicação:

29 de janeiro de 2018

Publicado:

30 de abril de 2018

Editor de área:

Renato Lima

\section{Palavras-chaves:}

AHP, TOPSIS, Ecoeficiência,

Transporte automotivo.

\section{Keywords:}

AHP, TOPSIS, Eco-efficiency,

Automotive Transport.

DOI:10.14295/transportes.v26i1.1313

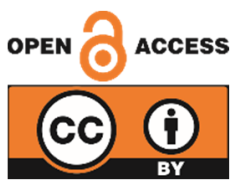

\begin{abstract}
RESUMO
É crescente a busca por alternativas de transporte mais sustentáveis, com uso de menos recursos e que causem menos impactos ao meio ambiente. Esta pesquisa busca avaliar a ecoeficiência de veículos leves para transporte de cargas, através de métodos de apoio à decisão, para orientar a escolha da alternativa com melhor desempenho econômico e ambiental. A avaliação de desempenho destes veículos foi desenvolvida com a utilização de um modelo híbrido composto de duas técnicas de apoio multicritério à decisão conhecidas: AHP e TOPSIS, para a classificação das alternativas. O modelo AHP-TOPSIS foi considerado robusto e bastante adequado para resolver esse tipo de problema. Os resultados desta pesquisa ajudam a identificar o nível de desempenho dos veículos e elaborar um ranking com base na ecoeficiência, o que ajudará a orientar o julgamento dos decisores no momento da escolha do veículo.
\end{abstract}

\section{ABSTRACT}

The search for more sustainable transportation alternatives, with the use of fewer resources and with less impact on the environment, is increasing. This research aims to evaluate the ecoefficiency of light vehicles for cargo transportation, through decision support methods, to guide the choice of the alternative with better economic and environmental performance. The performance evaluation of these vehicles was developed using a hybrid model composed of two known multicriteria decision techniques to classify the alternatives: AHP and TOPSIS. This model was considered robust and quite adequate to solve this type of problem. The results of this article aim to identify the performance level of the vehicles and to elaborate a ranking based on ecoefficiency, which will help to guide the judgment of the decision makers in the choice of the vehicle.

\section{INTRODUÇÃO}

A mobilidade da sociedade contemporânea enfrenta como grande desafio a busca pela sustentabilidade do transporte de passageiros e de cargas, em um cenário fortemente dependente de combustíveis fósseis, que impactam diretamente na crescente taxa de emissões de gases poluentes e causadores de efeito estufa. Em decorrência do seu alto impacto sobre o meio ambiente, o ponto de vista sustentável tem ganhado importância como parte do desenvolvimento de estratégias essenciais para empresas de transporte e logística (Oberhofer e Dieplinger, 2014).

A mobilidade pessoal é condição imprescindível para a humanidade, no acesso ao emprego, à educação e cultura, à troca de mercadorias e ao desenvolvimento socioeconômico dos povos, em uma economia globalizada. Além de fator essencial da liberdade individual, do crescimento econômico e da geração de riqueza, o transporte permite a extensão territorial das relações sociais e a troca de culturas (Philipon, 2010). 
Globalmente, mobilidade da sociedade contemporânea demanda alto consumo de energia (Zhou et al., 2014) e milhões de pessoas utilizam principalmente veículos alimentados por combustíveis fósseis (Sadeghzadeh e Salehi, 2011). No Brasil, até 2050, a atividade de transporte de carga crescerá em média $3,8 \%$ aa, com preponderância do transporte rodoviário, o que terá repercussões em $51 \%$ do diesel na demanda total do setor que continuará a ser o maior responsável por emissões de $\mathrm{CO}_{2}$ (EPE, 2014). Cada vez mais se percebe que o futuro do transporte rodoviário terá uma influência crucial nos esforços para avançar rumo a uma estratégia sustentável que aborde as restrições às emissões de gases efeito de estufa (GEE) e garanta a segurança energética a fim de evitar o rápido esgotamento dos recursos não renováveis (Maniatopoulos et al., 2015).

Dadas as complexas interações sociais, políticas e econômicas com os sistemas naturais, é urgente a necessidade de modelos matemáticos práticos aliados a soluções tecnológicas e analíticas para auxiliar gerentes e tomadores de decisões do mundo real (Gonzalez et al., 2015). Nas últimas décadas, várias abordagens de Apoio Multicritério à Decisão (AMD) têm sido propostas para avaliar a eficiência dos transportes, objetivando o desenvolvimento sustentável.

Estudos, teóricos e aplicados, têm utilizado o método TOPSIS para analisar o transporte automotivo ( Yousefi and Hadi-Vencheh, 2010; Kim et al., 2011; Xie et al., 2013; Tyagi et al., 2014; Lima Junior et al., 2015; Azizi et al., 2015; Puthanpura et al., 2015; Yang et al., 2015; Vinodh et al., 2016). Entretanto, no que concerne a avaliação do desempenho ambiental (Diabat et al. 2013; Tyagi et al., 2014; Jain et al., 2016), a literatura permanece escassa. É importante notar que nenhum deles discute a seleção de veículos de carga a partir de índices de ecoeficiência.

O objetivo deste artigo, fundamentado nas metodologias AHP e TOPSIS de apoio multicritério à decisão, é orientar decisores e consumidores, na avaliação da ecoeficiência de veículos utilitários leves a serem utilizados para o transporte de carga, tendo foco no menor consumo de combustível, aliado à menor emissão de poluentes e a maior capacidade de carga possível. Foram utilizados como referência os dados disponibilizados pelo Programa Nacional da Racionalização do Uso dos Derivados do Petróleo e do Gás Natural (Conpet), fornecidos pelo Inmetro, Petrobras e pelas respectivas montadoras das marcas e modelos dos automóveis analisados (Conpet, 2016).

O estudo contribui para compreender melhor o desempenho ambiental e econômico dos veículos leves para transporte de carga. Pode-se citar como contribuições específicas desta pesquisa: revisão da literatura de métodos de AMD da ecoeficiência no setor automotivo, processo de tomada de decisão em um caso real aplicado e a proposição e aplicação de um modelo híbrido para a avaliação da ecoeficiência entre veículos, além da análise de sensibilidade, que valida a robustez e confiabilidade da metodologia adotada bem como dos resultados encontrados. Os resultados podem chamar a atenção dos consumidores e fabricantes deste tipo de veículo sobre deficiências, bem como oportunidades de melhoria. Assim o estudo pode auxiliar as montadoras na melhoria da ecoeficiência, que é condição necessária para a sustentabilidade do transporte automotivo brasileiro no longo prazo.

\section{REFERENCIAL TEÓRICO}

Esta seção traz uma breve revisão de conceitos sobre transporte de cargas, veículos leves e ecoeficiência na mobilidade da sociedade contemporânea.

\subsection{Transporte de cargas}

Segundo Philipon (2010), no século XX, a revolução dos transportes favoreceu a abertura das sociedades e a aproximação das nações, possibilitando a troca de mercadorias e o estabelecimento da economia globalizada. Entretanto, este setor é um dos principais causadores dos gases efeito estufa e outros gases nocivos ao meio ambiente, sendo responsável por $20 \%$ das emissões globais de $\mathrm{CO}_{2}$ e por $9 \%$ no Brasil. Além do $\mathrm{CO}_{2}$, os veículos movidos a combustível fóssil são responsáveis por outros poluentes que degra- 
dam o ambiente e que são nocivos a saúde humana, dentre eles: monóxido de carbono (CO), hidrocarbonetos (HC), materiais particulados, óxidos de nitrogênio (NOx) e óxidos de enxofre (SOx) (Carvalho, 2011).

O crescimento demográfico, o processo de urbanização e a exploração intensiva das limitadas fontes de energia fósseis são tendências que se constituem em um desafio para mudanças, que afetam principalmente a mobilidade urbana. A mobilidade, apesar de essencial para as atividades humanas, encontrase pressionada pela sua peculiar alta demanda energética, pelo seu impacto no concorrido espaço urbano e pelas emissões ambientalmente prejudiciais (Philipon, 2010).

\subsection{Veículos leves de carga}

Segundo a Resolução no 396/2011 do Conselho Nacional de Trânsito, são considerados veículos leves; veículo automotor, utilitário, caminhonete e camioneta, com Peso Bruto Total (PBT) inferior a 3.500 kgf projetado para transporte de até 12 passageiros, ou seus derivados para o transporte de carga. PBT é o peso máximo que o veículo transmite ao pavimento, constituído da soma da tara com a lotação. Veículos de carga são aqueles destinados ao transporte de carga, podendo transportar até dois passageiros, exclusive o condutor (Brasil, 2011). Para fins desta pesquisa, foram selecionados apenas veículos leves de carga.

\subsection{Ecoeficiência na mobilidade da sociedade contemporânea}

Ecoeficiência é uma medida de melhoria da sustentabilidade e um dos principais critérios de avaliação do desempenho sustentável porque liga impactos ambientais diretamente com algum tipo de desempenho econômico (Rashidi e Farzipoor Saen, 2015), tornando-se uma ferramenta consistente - pelo uso de indicadores - para a transição para o desenvolvimento sustentável (Caiado et al. 2017) .

Conforme Picazo-Tadeo et al. (2012), ecoeficiência refere-se à: "capacidade das empresas, indústrias ou economias para produzir bens e serviços, enquanto incorrer menos impacto sobre o meio ambiente e consumir menos recursos naturais".

Para alcançar este objetivo e reduzir os impactos negativos dos transportes no meio ambiente e na sociedade, Ziolkowska e Ziolkowski (2015) definem que foram introduzidas desde 2006, estratégias de desenvolvimento sustentável e políticas operacionais objetivando incluir, dentre outros, a modernização da estrutura de serviços de transporte público de passageiros e de cargas, com destaque para os incentivos de melhorar a eficiência energética do setor.

No Brasil, políticas de amplo alcance foram implantadas desde a década de 1970, como o Programa Pró-álcool, as iniciativas do Proconve/Conama estabelecendo limites gradativamente decrescentes de emissões. Mais recente, o Programa Inovar Auto, trouxe iniciativas importantes, como o Programa Brasileiro de Etiquetagem Veicular (PBEV) e estímulos para uma renovação da frota, obtidas através da redução de alíquotas de IPI, já na década de 2010.

Segundo Hill (2010), a eficiência energética dos motores de combustão interna não passa de 15\%, e apesar da eficiência dos motores ter aumentado nos últimos anos (Meyer e Wessely, 2009), as emissões de gases causadores do efeito estufa continuam crescendo na frota mundial. Gases como monóxido de carbono (CO) e dióxido de enxofre $\left(\mathrm{SO}_{2}\right)$ foram reduzidos de forma bem sucedida com as tecnologias e políticas aplicadas nos motores nas últimas décadas. Contudo, outros gases, como óxidos de nitrogênio $\left(\mathrm{NO}_{\mathrm{x}}\right)$ e material particulado ainda estão crescentemente presentes na atmosfera (Pazdernil et al., 2010).

\section{METODOLOGIA DE PESQUISA}

Esta seção apresenta os métodos de apoio multicritério à decisão utilizados neste estudo para a avaliação da ecoeficiência de veículos, uma revisão de aplicações destes métodos na área automotiva e a proposição de um modelo híbrido a partir da junção destes métodos. 


\subsection{O Método AHP}

Conforme Gomes et al. (2004), a partir do Método de Análise Hierárquica, mais conhecido como AHP (Saaty,1980), o problema é dividido em níveis hierárquicos, o que facilita a compreensão e avaliação deste e ao final do método, busca-se priorizar ou classificar as alternativas. Por ser um método de baixa complexidade, que permite comparações paritárias e baseia-se em julgamentos de especialistas para derivar escalas de prioridade, tem sido amplamente aplicado por pesquisadores e tomadores de decisão (Vaidya e Kumar, 2006).

O método AHP objetiva analisar um problema qualitativo através de método quantitativo (Lolli et al. 2014), e utiliza a comparação par a par entre cada um dos critérios, subcritérios, alternativas e correlação entre níveis usando uma escala denominada nominal (Deng et al., 2014).

AHP é um método de apoio à decisão comumente empregado, tanto na pesquisa acadêmica, quanto nas aplicações de engenharia. Algumas características únicas do AHP são: clareza no entendimento e auxílio no tratamento de problemas complexos e de atributos múltiplos de várias áreas do conhecimento. Este método foi selecionado para a presente pesquisa por causa de seus recursos atraentes como: aplicação a dados quantitativos e qualitativos, utilização de estrutura hierárquica para apresentar problemas de decisão e provisão de medir a consistência do procedimento avaliado (Sindhu et al., 2017).

Em certos casos é necessário combinar o AHP com outros métodos de AMD, como o TOPSIS, um método favorável (Kaliszewski e Podkopaev, 2016), também considerado bastante prático e útil (Dinmohammadi e Shafiee, 2017).

Segundo Saaty (1980), Gomes et al. (2004) e Zhang (2016) o AHP clássico é um método de avaliação e decisão e suas principais etapas são:

(1) Construção de modelo de estruturação hierárquica de critérios através do estabelecimento da camada (níveis) de critérios.

(2) Matriz de comparação estrutural apresentada na Equação 1, em que as alternativas e os critérios são comparados par a par em matrizes de decisão quadradas usando-se a escala fundamental desenvolvida por Saaty apresentada na Tabela 1.

$$
A=\left(a_{i j}\right)_{n \times n}(i=1,2, \ldots, n), a_{i j}=1, a_{i j}=1 / a_{j i}
$$

em que $A$ é a matriz de julgamento e estabeleceu-se $a_{i j}$ que mostra o valor da comparação relativa entre o índice $a_{i}$ e o índice $a_{j}$.

$$
\begin{aligned}
& a_{i j}>0 \\
& \frac{1}{a_{i j}}=a_{j i} \\
& a_{i i}=1, a_{j j}=1
\end{aligned}
$$

(3) Normalização de matriz $A$ de julgamento (Equação 2):

$$
a_{i j}=a_{i j} / \sum_{j=1}^{n} a_{k j}(i=1,2, \ldots, n)
$$

(4) Somatório da linha da matriz de julgamento (Equação 3) para obter a prioridade relativa dos critérios.

$$
\omega_{i} \sum_{j=1}^{n} a_{i j}(i=1,2, \ldots, n)
$$

(5) vetor de prioridade $\omega_{i}$ é normalizado pela Equação 4:

$$
\omega_{i}=\omega_{i} / \sum_{i=1}^{n} \omega_{i}(i=1,2, \ldots, n)
$$


Tabela 1. Escala fundamental de Saaty (1980)

\begin{tabular}{lll}
\hline Pontuação & Conceito & Descrição \\
\hline 1 & Igual importância & $\begin{array}{l}\text { As duas atividades contribuem igualmente para o } \\
\text { objetivo. }\end{array}$ \\
3 & Importância pequena de uma sobre a outra & $\begin{array}{l}\text { A experiência e o juízo favorecem uma atividade em } \\
\text { relação à outra. } \\
\text { A experiência ou juízo favorece fortemente uma atividade } \\
\text { em relação à outra. }\end{array}$ \\
5 & Importância grande ou essencial & $\begin{array}{l}\text { Uma atividade é muito fortemente favorecida em relação } \\
\text { à outra. Pode ser demonstrada na prática. } \\
\text { A evidência favorece uma atividade em relação á outra, } \\
\text { com o mais alto grau de segurança. } \\
\text { Quando se procura uma condição de compromisso entre } \\
\text { definições. }\end{array}$ \\
\hline
\end{tabular}

Para Tomashevskii (2014), o método da média geométrica, apresentado na Equação 5, é semelhante ao método do autovetor, sendo igualmente adequados para medir e classificar elementos comparáveis com valores numéricos positivos. Esta equação deriva a prioridade dos elementos, sendo mais adequada para certas decisões em grupo (Dong et al., 2010). Após o cálculo da média geométrica dos elementos de cada linha, o vetor obtido é normalizado para obter o vetor prioridade (Mobinizadeh et al. 2016).

$$
\omega_{i}=C\left(\prod_{k=1}^{n} a_{i k}\right)^{1 / n},(i=1,2, \ldots, n)
$$

em que $C$ é um fator de normalização.

(6) Derivar o autovalor máximo $\left(\lambda_{\text {máx }}\right)$ e seu autovetor de acordo com a Equação 6:

$$
A \omega=\lambda_{\text {máx }} \omega
$$

Nesta etapa é determinada a importância relativa dos fatores pelo cálculo dos autovetores correspondentes ao máximo autovalor de comparação.

(7) Verificação de consistência (Equação 7):

$$
I C=\left(\lambda_{\text {máx }}-n\right) /(n-1)
$$

em que $I C$ é o índice de consistência e a matriz $A$ será consistente se: $\lambda_{\text {máx }} \geq n$ e $I C<0,1$.

Além disso, Saaty (1980) propõe o cálculo da Razão de Consistência $(R C)$, obtida pela fórmula demonstrada na Equação 8:

$$
R C=I C / I R
$$

Em que, IR é um índice aleatório, calculado para matrizes quadradas de ordem $n$ (Saaty, 1980).

\subsection{O Método TOPSIS}

Conforme Hwang et al. (1993), o TOPSIS (abreviação do inglês Technique for Order Preference by Similarity to Ideal Solution) técnica para ordenamento de preferência por similaridade pela solução ideal foi primeiramente desenvolvida por Hwang e Yoon (1981) a fim de solucionar um problema à tomada de decisão com múltiplos atributos e isso forneceu o princípio do compromisso em que a alternativa escolhida deve ser a de menor distância da Solução Ideal Positiva (SIP) e a de maior distância da Solução Ideal Negativa (SIN). Com isso, o TOPSIS minimiza a distância para a alternativa ideal enquanto maximiza a distância até o ponto ante-ideal. A solução ideal é formada tomando-se os melhores valores alcançados pelas alternativas, durante a avaliação em relação a cada critério de decisão, enquanto a solução ante-ideal é composta de forma similar, tomando-se os piores valores.

Segundo Olson (2004) e Barros e Wanke (2015), a aplicação do método TOPSIS pode ser expressa nas seguintes estapas: 
(1) Desenvolver matriz de avaliação com m alternativas e n critérios, sendo que a intersecção entre cada alternativa e critério é dada por $\mathrm{x}_{\mathrm{ij}}$, para o qual a matriz $\left(\mathrm{x}_{\mathrm{ij}}\right)_{\mathrm{mxn}}$ é obtida.

(2) Normalizar a matriz $\left(\mathrm{x}_{\mathrm{ij}}\right)_{\mathrm{mxn}}$ para $\mathrm{R}^{*}=\left(\mathrm{r}_{\mathrm{ij}}\right)$. Neste estudo, usou-se o método de normalização vetorial, conforme demonstrado na Equação 9:

$$
r_{i j}=\frac{x_{i j}}{\sqrt{\sum_{i=1}^{m} x_{i j}^{2}}}=1,2, \ldots \mathrm{m} \mathrm{e} \mathrm{j}=1,2, \ldots, \mathrm{n}
$$

(3) Ponderar matriz. Desenvolver um conjunto de constantes de escala $w_{\mathrm{k}}$ para cada um dos critérios. A base para esta ponderação pode ser o reflexo ad hoc da importância relativa. A ponderação da matriz é dada pela Equação 10:

$$
\text { - } v_{i j}=\left(w_{i j}\right)_{m \times n}=\left(w_{j} r_{i j}\right)_{m \times n}
$$

Em que, $\mathrm{w}_{\mathrm{j}}$ é a constante de escala dado para o critério $j$, e $\sum_{i=1}^{n} w_{j}=1$.

(4) Identificar a alternativa ideal ou (desempenho extremo em cada critério) ou SIP.

(5) Identificar a alternativa de ponto ante ideal ou (desempenho extremo reverso em cada critério) ou SIN.

(6) Obter medidas de distância com base em distância Euclidiana. Desenvolver uma medida de distância para cada ponto ideal $\left(\mathrm{D}^{+}\right)$e para cada ponto ante ideal (D-). dadas respectivamente pelas Equações 11 e 12:

$$
\begin{aligned}
& D_{i}^{+}=\sqrt{\sum_{j=1}^{m}\left(v_{i j}-s_{i j}^{+}\right)^{2}}, \text { para } \mathrm{i}=1,2, \ldots, \mathrm{m} \\
& D_{i}^{-}=\sqrt{\sum_{j=1}^{m}\left(v_{i j}-s_{i j}^{-}\right)^{2}}, \text { para } \mathrm{i}=1,2, \ldots, \mathrm{m}
\end{aligned}
$$

(7) . Para cada alternativa, determinar a razão R igual à distância para o ponto ante ideal dividido pela soma da distância ao ponto ante ideal e a distância para o ponto ideal (Equação 13).

$$
\mathrm{R}_{\mathrm{i}}=\mathrm{D}_{{ }_{\mathrm{i}}} /\left(\mathrm{D}_{\mathrm{i}}^{-}+\mathrm{D}_{\mathrm{i}}^{+}\right)
$$

(8) Obter a ordem de classificação das alternativas pela maximização da relação da etapa 7.

\subsection{TOPSIS aplicado ao transporte automotivo}

Nesta subseção fez-se um levantamento bibliográfico para identificar aplicações do método TOPSIS mobilidade automotiva, bem como observar as tendências de uso desta metodologia em pesquisas voltadas à ecoeficiência de transportes. Foram buscados artigos disponíveis a partir de 2009, nas bases de dados eletrônicos Elsevier, Scopus e Engineering Village.

A revisão sistemática da literatura apresentou distintas aplicações do método TOPSIS, em associação com outros métodos, em temas relacionados ao setor automotivo (Tabela 2).

Na maioria das publicações identificadas, os métodos mais usados foram o AHP-TOPSIS e o FuzzyTOPSIS. No que diz respeito ao método AHP-TOPSIS verifica-se que suas aplicações são voltadas principalmente para avaliar e selecionar itens e fornecedores da indústria automotiva. 
Tabela 2. Métodos usados no setor automotivo

\begin{tabular}{|c|c|c|c|c|c|c|c|c|c|c|c|}
\hline Ano & $\begin{array}{l}\text { Autores/ } \\
\text { Métodos }\end{array}$ & 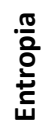 & 音 & $\underset{\mathbb{N}}{\stackrel{N}{L}}$ & $\begin{array}{l}\longleftarrow \\
\check{n} \\
o\end{array}$ & 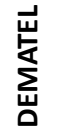 & $\sum_{<}^{0}$ & 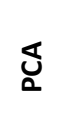 & 峁 & 㟔 & Aplicação \\
\hline 2010 & $\begin{array}{c}\text { Yousefi e } \\
\text { Hadi-Vencheh }\end{array}$ & & $x$ & & $x$ & & & & & $\mathrm{x}$ & $\begin{array}{l}\text { Avaliar de forma analítica as diferentes alternati- } \\
\text { vas automotivas para decidir sobre o automóvel } \\
\text { mais adequado no mercado }\end{array}$ \\
\hline 2011 & Kim et al. & & & $x$ & $x$ & & & & & & $\begin{array}{l}\text { Prever a difusão de produtos em um mercado } \\
\text { automotivo de tamanho completo. Propor } \\
\text { modelo para prever a dinâmica do mercado } \\
\text { quando um carro novo é lançado no mercado }\end{array}$ \\
\hline 2012 & Haldar et al. & & $x$ & & $x$ & & & & & & $\begin{array}{l}\text { Secionar fornecedores, considerando o cenário } \\
\text { de fabricantes de equipamento de automóvel }\end{array}$ \\
\hline 2013 & Xie et al. & $x$ & & & $x$ & & & & & & $\begin{array}{l}\text { Avaliação do desempenho de fornecedores de } \\
\text { serviço pós-venda em empresa automotiva }\end{array}$ \\
\hline 2014 & Tyagi et al. & & $x$ & & $X$ & & & & & & $\begin{array}{l}\text { Selecionar a melhor alternativa a fim de melhorar } \\
\text { o desempenho da gestão eletrônica da cadeia de } \\
\text { suprimentos da indústria automotiva }\end{array}$ \\
\hline 2015 & $\begin{array}{l}\text { Lima Junior et } \\
\text { al. }\end{array}$ & & $x$ & $\mathrm{X}$ & $x$ & & & & & & $\begin{array}{l}\text { Selecionar o fornecedor de uma empresa na } \\
\text { cadeia de produção automotiva }\end{array}$ \\
\hline 2015 & Yang et al. & & & $\mathrm{X}$ & $x$ & & & & & & $\begin{array}{l}\text { Avaliar o desempenho de materiais para tornar os } \\
\text { componentes automotivos mais remanufaturá- } \\
\text { veis, melhorando o processo de seleção de } \\
\text { materiais durante a fase inicial de projeto }\end{array}$ \\
\hline 2015 & Azizi et al. & & & $\mathrm{x}$ & $x$ & & & & & & $\begin{array}{l}\text { Selecionar o fornecedor mais adequado em um } \\
\text { sistema de cadeia de suprimentos e classificar } \\
\text { fornecedores automotivos }\end{array}$ \\
\hline 2015 & $\begin{array}{l}\text { Puthanpura et } \\
\text { al. }\end{array}$ & & & & $x$ & & & & & & $\begin{array}{l}\text { Selecionar a melhor tecnologia automotiva entre } \\
\text { três tecnologias emergentes identificadas e } \\
\text { avaliadas (comunicação Veículo-Veículo, Veículo- } \\
\text { Infra-Estrutura e Autónomo Completo) }\end{array}$ \\
\hline 2016 & Jain et al. & & $x$ & $x$ & $x$ & & & & & & Selecionar fornecedores de faróis \\
\hline 2016 & Vinodh et al. & & & $x$ & $x$ & $\mathrm{x}$ & $x$ & & & & $\begin{array}{l}\text { Selecionar o melhor conceito ágil de um compo- } \\
\text { nente (painel de instrumentos) de automóvel }\end{array}$ \\
\hline
\end{tabular}

\subsection{Proposição de modelo híbrido AHP-TOPSIS}

Pelo método AHP os critérios são classificados com base em constantes de escala, definidas a partir de prioridades atribuídas pelos especialistas a partir de comparação par-a-par. Busca-se o consenso do julgamento do grupo de especialistas, a fim de analisar a influência da ponderação dos diferentes critérios sob a escolha do veículo de carga mais ecoeficiente entre as alternativas avaliadas.

Já a metodologia TOPSIS representa a lógica do raciocínio da escolha humana, determina um valor escalar que responde simultaneamente às melhores e piores alternativas (Yildirim et al., 2016) sendo utilizada para ranquear as alternativas (Karahalios, 2017).

Entretanto, o TOPSIS é criticado devido à sua limitação em lidar adequadamente com a incerteza e a imprecisão inerentes ao processo de mapeamento das percepções dos decisores (Krohling e Campanharo, 2011). Para superar esta questão, assim como na pesquisa de Karahalios (2017), os métodos AHP e TOPSIS são combinados. AHP-TOPSIS é uma metodologia que permite diminuir a incerteza e a perda de informação na tomada de decisões em grupo para garantir uma solução robusta (Efe, 2016).

Recentemente, alguns modelos de AMD híbridos foram desenvolvidos para melhorar os pontos fortes e eliminar as desvantagens dos métodos clássicos, podendo auxiliar os decisores no tratamento de informações diversas, envolvendo as preferências das partes interessadas e critérios interligados ou contraditórios (Dinmohammadi e Shafiee, 2017).

Assim, para responder as lacunas desta pesquisa, um modelo de AMD híbrido combinando os méto- 
dos AHP e TOPSIS foi considerado apropriado. 0 método AHP é utilizado para a determinação da importância das constantes de escala (Salgado et al, 2011) enquanto o método TOPSIS é utilizado para a ordenar as alternativas (Hwang et al. 1993; Olson, 2004; Barros e Wanke, 2015; Vinodh et al., 2016). A Figura 1 ilustra as etapas do método proposto.

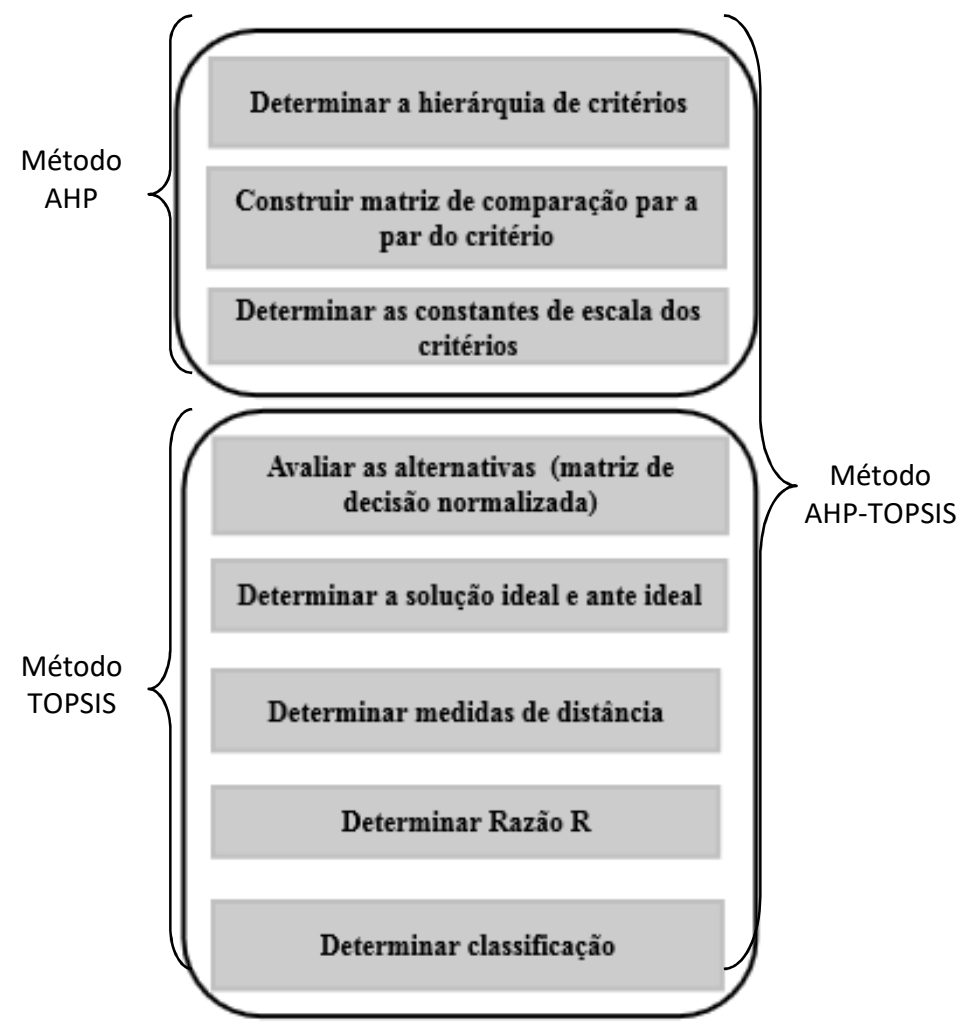

Figura 1. Etapas de aplicação do método AHP-TOPSIS

\section{ESTUDO DE CASO}

Desenvolveu-se um estudo de caso, por meio da aplicação de métodos multicritério, a fim de avaliar a ecoeficiência na mobilidade rodoviária da sociedade brasileira, através da avaliação comparativa dos parâmetros de onze veículos de carga leve, que são divulgados ao público através do Programa Brasileiro de Etiquetagem Veicular (PBEV), disponibilizada pelo Conpet (2016).

\subsection{Escopo, variáveis e base de dados}

Nesta pesquisa, os poluentes considerados para fins de avaliação das alternativas de transporte foram aqueles mensurados no âmbito do PBEV, a saber: o dióxido de carbono, resultante da combustão completa do carbono presente no combustível, importante atualmente devido à sua expressiva contribuição ao efeito estufa; o monóxido de carbono, resultante da combustão incompleta do carbono contido no combustível, gás extremamente tóxico; hidrocarbonetos não-metano, proveniente da combustão incompleta do combustível no motor, que compreende todas as substâncias orgânicas geradas no processo de combustão exceto o metano, precursor na formação do ozônio troposférico e óxidos de nitrogênio, formado pela reação de oxigênio e nitrogênio presentes na atmosfera sob condições de alta temperatura e elevada pressão, assim como os NMHC e os RCHO, são precursores do ozônio troposférico.

O Programa Brasileiro de Etiquetagem (PBE) que trouxe a base das informações e dos dados tratados neste artigo teve sua origem efetiva na década de 1980, foi inicialmente projetado para o setor automotivo e posteriormente foi redirecionado e ampliado para o setor de aparelhos eletrodomésticos. Seu foco é avaliar o desempenho energético dos produtos, com a finalidade de contribuir para a racionalização do uso da energia no Brasil. 
O PBE é atualmente coordenado pelo Inmetro, em parceria com o (Conpet) e o Programa Nacional de Conservação de Energia Elétrica, (Procel), duas iniciativas governamentais operacionalizadas, respectivamente, pela Petrobras e pela Eletrobrás. A partir deste programa, podem-se levar em consideração outros atributos além do preço no momento da aquisição dos produtos, assim como estimular a competitividade da indústria através da indução do processo de melhoria contínua promovida pela escolha consciente dos consumidores (Simão, 2011).

A Etiquetagem é uma forma de evidenciar o atendimento aos requisitos de desempenho dos veículos estabelecidos em normas e regulamentos técnicos. Os veículos avaliados ficam autorizados a ostentar a um selo, que classifica os veículos em faixas de " $A$ " (mais eficiente) a " $E$ " (menos eficiente), e fornece outras informações relevantes, como por exemplo, as emissões dos motores causadores de gases poluentes e de efeito estufa. Tais informações são apresentadas ao público consumidor, conforme Figura 2.

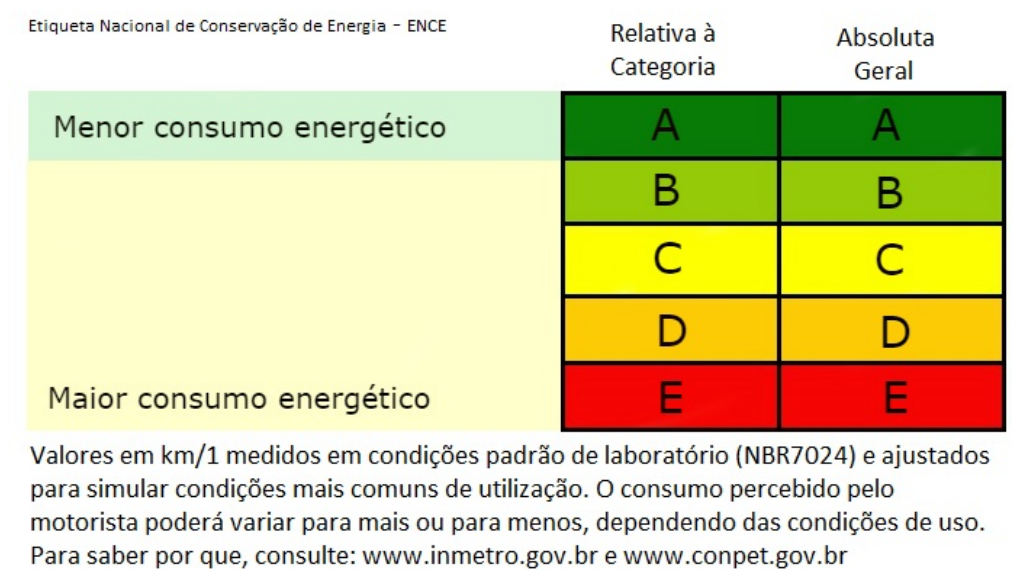

Figura 2. Etiqueta Nacional de Conservação de Energia (Conpet, 2016)

Para fins desta pesquisa, foi feito um levantamento de dados na base do portal Conpet (2016) em que os tomadores de decisão do Inmetro selecionaram todos os veículos de carga derivados de carros de passeio, com motor flex, à venda no mercado brasileiro no ano de 2016. A partir disso, foram selecionadas onze alternativas de veículos leves da categoria veículo comercial derivado (capacidade de carga de $500 \mathrm{kgf}$ a $1000 \mathrm{kgf}$ ), movidos a etanol e gasolina, que foram enumeradas de $\mathrm{A}_{1}$ a $\mathrm{A}_{11}$. Estas alternativas foram selecionadas em função da tipologia do veículo, todos voltados para o transporte urbano de cargas e com base no tipo de combustível, onde foram elencados apenas os veículos com motorização ciclo Otto, devido a seu menor custo de aquisição.

A aplicação dos métodos se deu sobre as alternativas a fim de verificar qual destes veículos atende melhor às dimensões econômica e ambiental da sustentabilidade. Foram considerados sete critérios enumerados de $\mathrm{C}_{1}$ a $\mathrm{C}_{7}$, conforme Tabela 3 (Conpet, 2016).

Os critérios $\mathrm{C}_{1}$ a $\mathrm{C}_{6}$ utilizados no estudo foram avaliados conforme normas que prescrevem o método para a medição do consumo de combustível de veículos rodoviários automotores leves, através de ciclos de condução que simulam o uso do veículo no trânsito urbano e de estrada. A determinação de hidrocarbonetos ( $\mathrm{HC}$ ), monóxido de carbono (CO), óxidos de nitrogênio (NOx) e dióxido de carbono $\left(\mathrm{CO}_{2}\right)$ emitidos pelo motor de veículos rodoviários automotores leves, sob condições simuladas de uso normal médio aplicáveis a veículos equipados com motores ciclo Otto que utilizam gasolina, ou etanol, ou misturas de ambos como combustíveis (ABNT 2001; 2017). Além destes, foi incluído o critério Capacidade de Carga $\left(\mathrm{C}_{7}\right)$, que reflete a utilidade finalística de cada alternativa, e foi priorizado pelos decisores na aplicação do método.

O objetivo pretendido nesta análise consiste em minimizar os critérios que representam aspectos ambientais e maximizar os critérios econômicos. 
Tabela 3. Critérios de avaliação

\begin{tabular}{lllll}
\hline Tipo & Siglas & Critérios & Unidades & Objetivo \\
\hline Ambiental & $C_{1}$ & Emissões de NMHC & $\mathrm{g} / \mathrm{km}$ & Minimizar \\
Ambiental & $C_{2}$ & Emissões de CO & $\mathrm{g} / \mathrm{km}$ & Minimizar \\
Ambiental & $\mathrm{C}_{3}$ & Emissões de NOx & $\mathrm{g} / \mathrm{km}$ & Minimizar \\
Ambiental & $\mathrm{C}_{4}$ & Emissões de $\mathrm{CO}_{2}$ fóssil & $\mathrm{g} / \mathrm{km}$ & Minimizar \\
Econômico & $\mathrm{C}_{5}$ & Consumo de combustivel & $\mathrm{km} / \mathrm{l}$ & Maximizar \\
Ambiental & $\mathrm{C}_{6}$ & Consumo Energético & $\mathrm{MJ} / \mathrm{km}$ & Minimizar \\
Econômico & $\mathrm{C}_{7}$ & Capacidade de carga & $\mathrm{Kg}$ & Maximizar \\
\hline
\end{tabular}

Desta forma, as alternativas foram avaliadas com relação aos critérios, sendo cinco critérios ambientais e dois critérios econômicos. Destaca-se que há critérios de minimização $\left(\mathrm{C}_{1}, \mathrm{C}_{2}, \mathrm{C}_{3}, \mathrm{C}_{4}\right.$ e $\left.\mathrm{C}_{6}\right)$ e critérios de maximização $\left(\mathrm{C}_{5}\right.$ e $\left.\mathrm{C}_{7}\right)$.

\subsection{Aplicação do AHP-TOPSIS para avaliar a ecoeficiência dos transportes}

A partir desta etapa, propôs-se a aplicação do método AHP-TOPSIS que utiliza a sequência do método AHP para determinar a importância relativa dos critérios em conjunto com o método TOPSIS para ordenar as alternativas em relação à sua melhor ecoeficiência para o transporte urbano de cargas, comparando o desempenho de cada uma delas em relação aos critérios avaliados. 0 método AHP-TOPSIS, ilustrado na Figura1, foi aplicado por meio das seguintes etapas:

Etapa 1: Desenvolver modelo de hierarquia com base nos critérios:

Etapa 2: Construir matriz de comparação (Tabela 4), a fim de obter os pesos par a par dos elementos do nível da hierarquia mostrada. As preferências dos decisores são identificadas usando a escala de Saaty (Tabela 1). Estas preferências foram obtidas através de consenso dos decisores, que foram obtidas a partir de duas reuniões com o grupo de especialistas da área automotiva do Inmetro nos meses de outubro e novembro de 2016, nas quais foi feito um levantamento dentre os participantes, que culminou com a matriz de decisão apresentada na Tabela 4.

Tabela 4. Matriz de comparação dos critérios

\begin{tabular}{llllllll}
\hline & $\mathbf{C}_{\mathbf{1}}$ & $\mathbf{C}_{\mathbf{2}}$ & $\mathrm{C}_{\mathbf{3}}$ & $\mathbf{C}_{\mathbf{4}}$ & $\mathrm{C}_{5}$ & $\mathrm{C}_{6}$ & $\mathrm{C}_{\mathbf{7}}$ \\
\hline $\mathrm{C}_{1}$ & 1 & 0,2 & 3 & 4 & 0,3333 & 0,25 & 0,1667 \\
$\mathrm{C}_{2}$ & 5 & 1 & 6 & 7 & 4 & 3 & 0,3333 \\
$\mathrm{C}_{3}$ & 0,3333 & 0,1667 & 1 & 3 & 0,2500 & 0,2 & 0,1429 \\
$\mathrm{C}_{4}$ & 0,2500 & 0,1429 & 0,3333 & 1 & 0,2000 & 0,1667 & 0,1250 \\
$\mathrm{C}_{5}$ & 3 & 0,25 & 4 & 5 & 1 & 0,3333 & 0,2000 \\
$\mathrm{C}_{6}$ & 4 & 0,3333 & 5 & 6 & 3 & 1 & 0,2500 \\
$\mathrm{C}_{7}$ & 6 & 3 & 7 & 8 & 5 & 4 & 1 \\
\hline
\end{tabular}

Etapa 3: Determinar as constantes de escala dos critérios. Nesta etapa, calculou-se o vetor de prioridades dos critérios por meio do cálculo do valor normalizado da média geométrica das linhas da matriz de comparação. A Tabela 5 expressa a prioridade, o respectivo vetor de prioridade dos critérios e o valor da Razão de Consistência (RC) é de 0,0819 e é obtido com $\mathrm{IR}=1,32(\mathrm{n}=7)$ e $\lambda_{\text {máx }}$ médio $=7,6486$.

Tabela 5. Vetor de prioridade dos critérios

\begin{tabular}{llllllll}
\hline Prioridades & $\mathbf{C}_{1}$ & $\mathbf{C}_{2}$ & $\mathbf{C}_{3}$ & $\mathbf{C}_{4}$ & $\mathbf{C}_{5}$ & $\mathbf{C}_{6}$ & $\mathbf{C}_{\mathbf{7}}$ \\
\hline Vetor de prioridades & 0,058 & 0,2468 & 0,036 & 0,0229 & 0,0943 & 0,1533 & 0,3886 \\
\hline
\end{tabular}

Pelo resultado do RC, percebe-se que a inconsistência dos juízos emitidos foi aceitável, pois é menor do que 0,10 . 
Etapa 4: Desenvolver matriz de avaliação. A Tabela 6 apresenta a matriz de decisão, com as onze alternativas e os seus respectivos desempenhos nos sete critérios. Posteriormente, os valores são normalizados e ponderados, conforme procedimento do método TOPSIS apresentado na equação 9. Depois os valores do melhor desempenho (SIP) e do pior desempenho (SIN) são definidos.

Tabela 6. Matriz de avaliação

\begin{tabular}{cccccccc}
\hline Transportes & $\mathbf{C}_{\mathbf{1}}$ & $\mathbf{C}_{\mathbf{2}}$ & $\mathbf{C}_{\mathbf{3}}$ & $\mathbf{C}_{\mathbf{4}}$ & $\mathbf{C}_{\mathbf{5}}$ & $\mathbf{C}_{\mathbf{6}}$ & $\mathbf{C}_{\mathbf{7}}$ \\
\hline $\mathrm{A}_{\mathbf{1}}$ & 0,03 & 0,66 & 0,01 & 121,00 & 10,40 & 1,99 & 768,00 \\
$\mathrm{~A}_{2}$ & 0,01 & 0,29 & 0,03 & 119,00 & 10,70 & 1,92 & 650,00 \\
$\mathrm{~A}_{3}$ & 0,02 & 0,49 & 0,03 & 126,00 & 10,00 & 2,08 & 650,00 \\
$\mathrm{~A}_{4}$ & 0,02 & 0,33 & 0,04 & 127,00 & 10,30 & 2,07 & 705,00 \\
$\mathrm{~A}_{5}$ & 0,02 & 0,33 & 0,04 & 127,00 & 10,30 & 2,07 & 685,00 \\
$\mathrm{~A}_{6}$ & 0,02 & 0,42 & 0,02 & 123,00 & 10,50 & 2,00 & 712,00 \\
$\mathrm{~A}_{7}$ & 0,02 & 0,43 & 0,02 & 117,00 & 10,80 & 1,89 & 668,00 \\
$\mathrm{~A}_{8}$ & 0,03 & 0,40 & 0,02 & 114,00 & 10,90 & 1,87 & 668,00 \\
$\mathrm{~A}_{9}$ & 0,02 & 0,36 & 0,02 & 117,00 & 10,90 & 1,89 & 623,00 \\
$\mathrm{~A}_{10}$ & 0,02 & 0,37 & 0,04 & 133,00 & 9,60 & 2,17 & 650,00 \\
$\mathrm{~A}_{11}$ & 0,03 & 0,46 & 0,03 & 149,00 & 8,30 & 2,40 & 650,00 \\
\hline
\end{tabular}

Etapas 5: Obter medidas de distância, com base em distância Euclidiana, determinação da razão R e classificação, apresentados na Tabela 7.

Tabela 7. Medidas de Distância, razão R e ordem de classificação

\begin{tabular}{lllll} 
& $\mathbf{D}^{+}$ & $\mathbf{D}^{-}$ & $\mathbf{R}$ & Ordem \\
\hline$A_{1}$ & 0,0651 & 0,0295 & 0,3122 & 11 \\
$A_{2}$ & 0,0213 & 0,0668 & 0,7582 & 3 \\
$A_{3}$ & 0,0420 & 0,0315 & 0,4282 & 10 \\
$A_{4}$ & 0,0161 & 0,0614 & 0,7927 & 1 \\
$A_{5}$ & 0,0186 & 0,0607 & 0,7656 & 2 \\
$A_{6}$ & 0,0255 & 0,0469 & 0,6475 & 5 \\
$A_{7}$ & 0,0302 & 0,0443 & 0,5943 & 8 \\
$A_{8}$ & 0,0278 & 0,0481 & 0,6337 & 7 \\
$A_{9}$ & 0,0284 & 0,0552 & 0,6607 & 4 \\
$A_{10}$ & 0,0284 & 0,0520 & 0,6470 & 6 \\
$A_{11}$ & 0,0406 & 0,0355 & 0,4665 & 9 \\
\hline
\end{tabular}

Conforme a análise da Tabela 7 percebe-se que a ordem de classificação das alternativas mais ecoeficientes, a partir dos critérios selecionados, seria: A4 > A5 > A2 > A9 > A6 > A10 > A8 >A7 > A11 > A3 > A1.

\subsection{Análise de Sensibilidade}

Após a classificação das alternativas, para verificar a consistência e robustez dos resultados obtidos, foi conduzida uma análise de sensibilidade ajustando-se as constantes de escala de acordo com diferentes valores de ordem de importância dos critérios. Para isso, foram realizadas entrevistas com cinco especialistas no assunto, pertencentes ao corpo de pesquisadores do Inmetro, que elencaram graus de importância distintos para dois critérios de decisão, a partir da sua percepção quanto ao nível de impacto ambiental e econômico de cada um no desempenho esperado de cada veículo, em relação aos parâmetros de ecoeficiência mais desejados. Assim, foram propostos 11 situações distintas, que serão denominadas como casos, conforme mostrado na Tabela 8 . 0 caso 0 ignora a aplicação do método AHP, considerando o mesmo grau de importância entre os critérios e representa apenas o resultado do método TOPSIS. 0 caso 1 foi construído com base na decisão de especialistas do Inmetro e os casos 2 e 3 constituem 
análises de sensibilidade do caso 1 com variações de $10 \%$ no valor de $C_{7}$ para menos e para mais respectivamente. De forma adicional, foram elaborados sete novos casos, que consideram diferentes prioridades para os critérios ambientais ou econômicos, construídas a partir de comparações paritárias no método AHP de acordo com a razão de consistência, gerando variações nas constantes de escala e variações na classificação das alternativas. Deve-se ressaltar que estas constantes de escala foram arbitradas para realização desta análise.

Tabela 8. Combinação de constantes de escala e RC no método AHP para análise de sensibilidade

\begin{tabular}{|c|c|c|c|c|c|c|c|c|c|}
\hline \multirow{2}{*}{ Caso } & \multirow{2}{*}{ Ordem de importância } & \multicolumn{7}{|c|}{ Constantes de escala } & \multirow{2}{*}{ RC } \\
\hline & & $\mathrm{C}_{1}$ & $C_{2}$ & $\mathrm{C}_{3}$ & $\mathrm{C}_{4}$ & $\mathrm{C}_{5}$ & $\mathrm{C}_{6}$ & $C_{7}$ & \\
\hline 0 & $\mathrm{C}_{1}=\mathrm{C}_{2}=\mathrm{C}_{3}=\mathrm{C}_{4}=\mathrm{C}_{5}=\mathrm{C}_{6}=\mathrm{C}_{7}=\mathrm{C}_{8}$ & $14 \%$ & $14 \%$ & $14 \%$ & $14 \%$ & $14 \%$ & $14 \%$ & $14 \%$ & - \\
\hline $1^{*}$ & & $6 \%$ & $25 \%$ & $4 \%$ & $2 \%$ & $9 \%$ & $15 \%$ & $39 \%$ & 0,0819 \\
\hline 2 & $C_{7}>C_{2}>C_{6}>C_{5}>C_{1}>C_{3}>C_{4}$ & $6 \%$ & $26 \%$ & $4 \%$ & $3 \%$ & $10 \%$ & $16 \%$ & $35 \%$ & - \\
\hline 3 & & $5 \%$ & $24 \%$ & $3 \%$ & $2 \%$ & $9 \%$ & $15 \%$ & $42 \%$ & - \\
\hline 4 & $C_{2}>C_{7}>C_{4}>C_{6}>C_{5}>C_{1}>C_{3}$ & $4 \%$ & $36 \%$ & $3 \%$ & $16 \%$ & $7 \%$ & $10 \%$ & $24 \%$ & 0,0225 \\
\hline 5 & $C_{3}>C_{7}>C_{2}>C_{4}>C_{6}>C_{5}>C_{1}$ & $3 \%$ & $16 \%$ & $35 \%$ & $10 \%$ & $4 \%$ & $7 \%$ & $24 \%$ & 0,0246 \\
\hline 6 & $C_{4}>C_{7}>C_{2}>C_{3}>C_{6}>C_{5}>C_{1}$ & $3 \%$ & $16 \%$ & $10 \%$ & $35 \%$ & $4 \%$ & $7 \%$ & $24 \%$ & 0,0246 \\
\hline 7 & $C_{5}>C_{7}>C_{4}>C_{3}>C_{6}>C_{2}>C_{1}$ & $3 \%$ & $4 \%$ & $10 \%$ & $16 \%$ & $35 \%$ & $7 \%$ & $24 \%$ & 0,0295 \\
\hline 8 & $\mathrm{C}_{6}>\mathrm{C}_{7}>\mathrm{C}_{1}>\mathrm{C}_{3}>\mathrm{C}_{5}>\mathrm{C}_{4}>\mathrm{C}_{2}$ & $16 \%$ & $3 \%$ & $10 \%$ & $4 \%$ & $7 \%$ & $35 \%$ & $24 \%$ & 0,0246 \\
\hline 9 & $C_{1}>C_{6}>C_{2}>C_{3}>C_{5}>C_{4}>C_{7}$ & $35 \%$ & $16 \%$ & $10 \%$ & $4 \%$ & $7 \%$ & $24 \%$ & $3 \%$ & 0,0246 \\
\hline 10 & $C_{2}>C_{4}>C_{1}>C_{3}>C_{6}>C_{5}>C_{7}$ & $16 \%$ & $35 \%$ & $10 \%$ & $24 \%$ & $5 \%$ & $6 \%$ & $3 \%$ & 0,0194 \\
\hline
\end{tabular}

* Combinação de constantes de escala conforme consenso de especialistas

Percebe-se que a abordagem AHP é construída de acordo com objetivos dos decisores que, embora busquem identificar os veículos mais ecoeficientes, podem ter interesses diferentes, com foco maior na dimensão ambiental ou na dimensão econômica. Os resultados da análise de sensibilidade são apresentados na Tabela 9.

Tabela 9. Análise de sensibilidade do AHP-TOPSIS

\begin{tabular}{|c|c|c|c|c|c|c|c|c|c|c|c|}
\hline \multirow{2}{*}{ Caso } & \multicolumn{11}{|c|}{ Alternativas } \\
\hline & $\overline{A_{1}}$ & $A_{2}$ & $A_{3}$ & $\mathbf{A}_{4}$ & $A_{5}$ & $A_{6}$ & $A_{7}$ & $A_{8}$ & $A_{9}$ & $A_{10}$ & $A_{11}$ \\
\hline 0 & 0,5117 & 0,6825 & 0,4607 & 0,5519 & 0,5500 & 0,6820 & 0,6309 & 0,6071 & 0,6849 & 0,4098 & 0,3921 \\
\hline 1 & 0,3122 & 0,7582 & 0,4282 & 0,7927 & 0,7656 & 0,6475 & 0,5943 & 0,6337 & 0,6607 & 0,6470 & 0,4665 \\
\hline 2 & 0,2913 & 0,7821 & 0,4358 & 0,7996 & 0,7779 & 0,6492 & 0,6046 & 0,6461 & 0,6868 & 0,6619 & 0,4751 \\
\hline 3 & 0,3263 & 0,7408 & 0,4222 & 0,7910 & 0,7587 & 0,6466 & 0,5862 & 0,6262 & 0,6416 & 0,6390 & 0,4617 \\
\hline 4 & 0,1925 & 0,8732 & 0,4520 & 0,8551 & 0,8455 & 0,6501 & 0,6259 & 0,6829 & 0,7689 & 0,7378 & 0,5107 \\
\hline 5 & 0,7173 & 0,5185 & 0,4747 & 0,3505 & 0,3481 & 0,7651 & 0,6455 & 0,6814 & 0,6583 & 0,2408 & 0,4797 \\
\hline 6 & 0,5003 & 0,7029 & 0,4912 & 0,6089 & 0,6018 & 0,6990 & 0,6648 & 0,7051 & 0,7013 & 0,4842 & 0,3947 \\
\hline 7 & 0,7569 & 0,6103 & 0,5153 & 0,5051 & 0,4938 & 0,7635 & 0,6944 & 0,7104 & 0,6609 & 0,3233 & 0,3035 \\
\hline 8 & 0,5912 & 0,6694 & 0,4539 & 0,5368 & 0,5278 & 0,6611 & 0,6339 & 0,5640 & 0,6265 & 0,3212 & 0,2527 \\
\hline 9 & 0,3337 & 0,8281 & 0,4086 & 0,6925 & 0,6924 & 0,5785 & 0,5678 & 0,4373 & 0,6465 & 0,4649 & 0,2632 \\
\hline 10 & 0,2722 & 0,8506 & 0,4560 & 0,7580 & 0,7580 & 0,6492 & 0,6290 & 0,6483 & 0,7738 & 0,6405 & 0,4687 \\
\hline
\end{tabular}

A análise de sensibilidade mostra que os resultados da abordagem integrada AHP-TOPSIS são bastante sensíveis à constante de escala, ou seja, a prioridade atribuída aos critérios de avaliação. 0 resultado mostra que a avaliação dos decisores é uma etapa muito crítica para avaliar a ecoeficência e suas decisões e experiências contribuem bastante para a determinação do processo de seleção.

A Figura 3 mostra diferentes resultados de desempenho para as diferentes combinações de constantes de escala.

Analisando a Figura 3, percebe-se que as alternativas A2 e A4 permanecem bem pontuadas na maioria dos casos de decisão. Ambas as alternativas são modelos de veículos diferentes de uma mesma montadora, que utilizam um mesmo motor de concepção moderna e capacidade cúbica de $1,4 \mathrm{~cm}^{3}$. Ou seja, sob o ponto de vista da tecnologia em motores, a recente tendência do downsizing se mostra efetiva 
quando o objetivo é redução do consumo e do nível de emissões, mantendo-se praticamente inalterada a capacidade de carga. Foram descartados parâmetros de desempenho relacionados à velocidade e taxa de aceleração, por serem critérios considerados não decisivos para a seleção deste tipo de veículo.

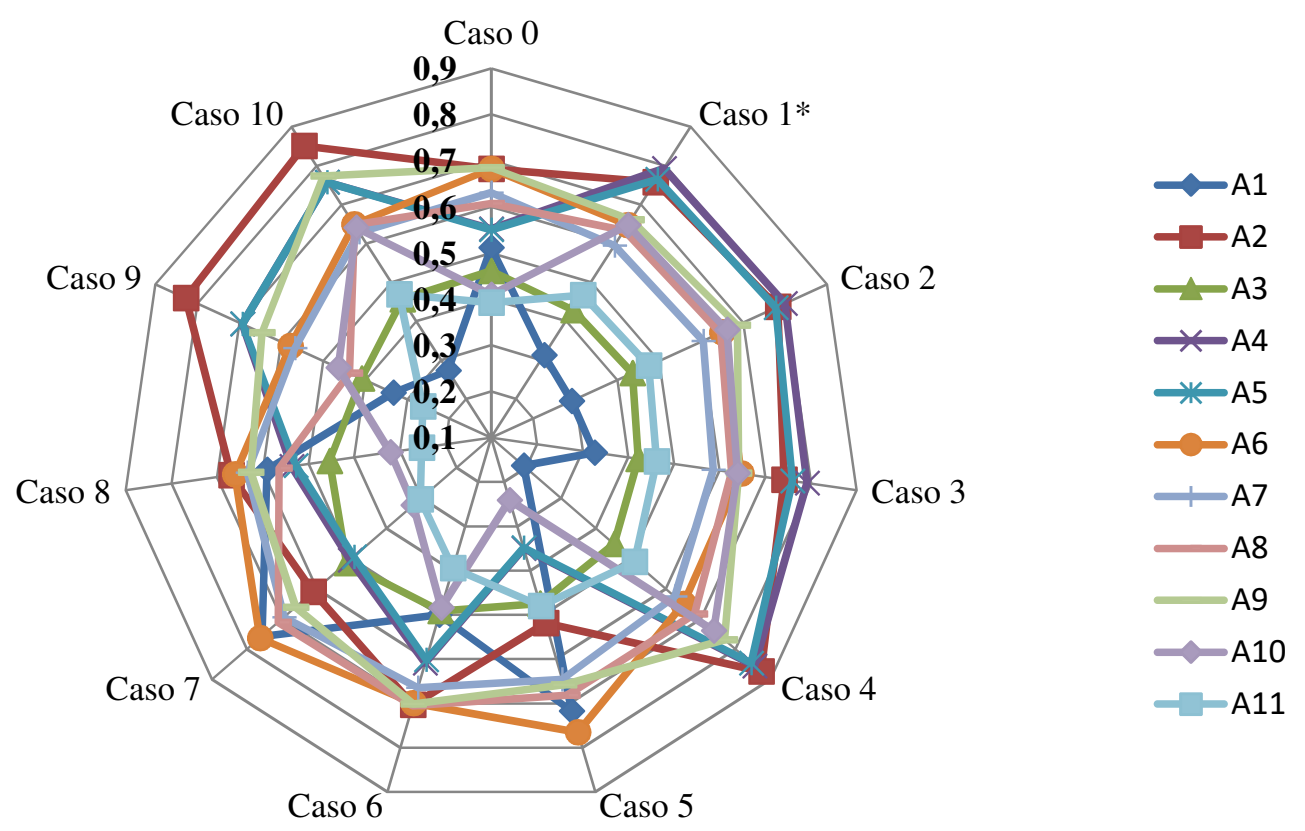

Figura 3. Análise de sensibilidade da ecoeficiência dos veículos de carga

A picape $\mathrm{A}_{1}$ é a que tem a maior capacidade de carga dentre as alternativas avaliadas. No entanto, é penalizada por um elevado índice de emissões de CO e de NMHC, o que coloca esta alternativa em desvantagem extrema quando critérios ambientais são mais valorados nos casos de decisão.

A alternativa $A_{3}$ tem reduzida capacidade de carga e reduzida eficiência energética, fato que pode ser atribuído ao seu propulsor $1,6 \mathrm{~cm}^{3}$ de 16 válvulas, mais voltado ao desempenho esportivo do que ao transporte de cargas, caracterizando o veículo como uma picape esporte.

0 veículo $A_{5}$ apresenta os mesmos índices econômicos e ambientais do $\mathrm{A}_{4}$, pois é a versão com mesma motorização, mas com cabine estendida, refletindo negativamente apenas na sua capacidade de carga, gerando-lhe pequena desvantagem em relação ao líder, sempre que este parâmetro é valorizado pelos decisores.

As picapes representadas pelas alternativas $A_{6}, A_{7}$ e $A_{8}$ são variações do mesmo modelo, com diferenças em termos de acabamento e altura da suspensão, mas todas com mesma motorização o que se reflete em comportamentos bastante semelhantes analisando-se qualquer parâmetro sob quaisquer casos.

0 veículo representado pela alternativa $A_{9}$ somente ganha destaque quando os parâmetros são todos avaliados sem distinção de importância, porque apesar de suas reduzidas emissões e seu excelente desempenho energético, a capacidade de carga é a menor dentre os concorrentes, por ter cabine dupla, fato que o desfavorece sob o viés econômico deste estudo.

Finalmente, dentre as alternativas de veículos que apresentaram os piores desempenhos globais em todos os casos avaliados, as picapes $\mathrm{A}_{10}$ e $\mathrm{A}_{11}$ se revezaram nas últimas posições. Mais uma vez, a análise de sensibilidade se mostra bastante coerente, pois são sensíveis as diferenças entre estes veículos e os demais concorrentes, no que se refere à tecnologia de motores e transmissões e sua capacidade de carga.

A alternativa $A_{10}$ avaliada no âmbito do PBEV apresentou baixa capacidade de carga e o segundo maior consumo energético, devido ao seu motor multiválvulas de tecnologia já obsoleta, desenvolvido ainda na década de 1990. 
A picape $A_{11}$, por sua vez, segundo dados fornecidos pelo Conpet, além da baixa capacidade de carga, é comercializada com motor de $1,8 \mathrm{~cm}^{3}$ e câmbio automático, fatos que somados a desfavorecem sobremaneira em relação ao consumo energético diante dos demais concorrentes.

\section{CONCLUSÕES}

A aplicação do método AHP como ferramenta auxiliar na tomada de decisão resultou na indicação da ordem prioritária de critérios para a posterior classificação dos onze veículos, por meio do método TOPSIS, no que diz respeito aos sete critérios de desempenho de ecoeficiência, a qual permitiu uma análise detalhada das alternativas, servindo como benchmarking na escolha de transportes mais sustentáveis. Desta forma, verifica-se a relevância dos métodos de Apoio à Decisão no levantamento de alternativas de transporte em um processo decisório, principalmente quando os métodos são de fácil implementação e entendimento pelos atores, propiciando a discussão e contribuindo bastante para a seleção de um veículo utilitário leve mais ecoeficiente a ser utilizado para transporte de carga.

Conclui-se que as vertentes ambiental e econômica da sustentabilidade podem orientar a busca por alternativas de transporte mais ecoeficientes, considerando critérios quantitativos relativos aos veículos, cujos dados são de acesso público através do portal do Conpet (2016). Verifica-se que a alternativa que apresentou o melhor desempenho, segundo os critérios selecionados para esta análise foi a alternativa $\mathrm{A}_{4}$, de acordo com o caso original. Analisando a matriz de decisão, verifica-se que esta alternativa apresenta alto índice de capacidade de carga, baixo nível de emissão de poluentes, apesar de não ser a mais eficiente em termos de consumo de combustível e eficiência energética. Mas a quantificação de seu desempenho geral nos sete critérios fica comprovada com a aplicação dos métodos de apoio à decisão.

Identificam-se ainda, dentre as alternativas avaliadas, que $A_{5}, A_{2}, A_{9}$ e $A_{6}$ apresentam, nesta ordem, bons desempenhos. As alternativas $A_{10}$ e $A_{11}$ não demonstraram eficiência para uso no transporte de carga e as alternativas $A_{3}$ e $A_{1}$ são as que apresentam os piores desempenhos ambientais, principalmente devido ao seu alto índice de emissões de CO, critério considerado crítico sob o aspecto ambiental, comprovando as expectativas dos especialistas.

Ao final deste estudo, também foram feitas análises de sensibilidade para múltiplos e diferentes casos, obtidos através de diferentes quantificações das constantes de escala dos critérios para validar os resultados, trazendo confiabilidade e robustez para o método aplicado. Uma sugestão de trabalho futuro compreende a consideração de outras dimensões da sustentabilidade e da incerteza através do uso de métodos AMD como o fuzzy TOPSIS.

\section{ACKNOWLEDGEMENTS}

Ao CNPq e a CAPES pelo apoio financeiro.

\section{REFERENCES}

ABNT (2001) NBR 6601 - Veiculos Rodoviarios Automotores Leves - Determinacao de hidrocarbonetos, monoxido de carbono, óxidos de nitrogênio e dióxido de carbono no escapamento. Associação Brasileira de Normas Técnicas, Rio de Janeiro.

ABNT (2017) NBR 7024 - Veículos Rodoviários Automotores Leves - Medição do Consumo de Combustível - Método de Ensaio. Associação Brasileira de Normas Técnicas, Rio de Janeiro.

Azizi, A.; D.O. Aikhuele e F.S. Souleman, (2015). A Fuzzy \{TOPSIS\} Model to Rank Automotive Suppliers. Procedia Manufacturing, v. 2, p. 159-164. DOI: 10.1016/j.promfg.2015.07.028

Barros, C.P. e P. Wanke (2015). An analysis of African airlines efficiency with two-stage TOPSIS and neural networks. Journal of Air Transport Management, v. 44-45, p. 90-102. DOI: 10.1016/j.jairtraman.2015.03.002

Brasil (2001) Decreto no 4.059, de 19 de dezembro de 2001 Regulamenta a Lei no 10.295, de 17 de outubro de 2001, que dispõe sobre a Política Nacional de Conservação e Uso Racional de Energia, e dá outras providências. Brasília, 19 de dezembro de 2001. Disponível em: http://www.planalto.gov.br/ccivil_03/decreto/2001/d4059.htm. (Acessado em 27/05/2016).

Brasil. Ministério do Meio Ambiente (2013) Inventário Nacional de Emissões Atmosféricas por Veículos Automotores Rodoviários. Janeiro de 2011. Disponível em: http://www.mma.gov.br/estruturas/163/_publicacao/163_publicacao27072011055200.pdf. (Acesso em: 27/05/2016) 
Brasil (2011) Resolução no 396/2011 do Conselho Nacional de Trânsito (CONTRAN). Dispõe sobre requisitos técnicos mínimos para a fiscalização da velocidade de veículos automotores, reboques e semirreboques, conforme o Código de Trânsito Brasileiro. 13 de dezembro de 2011. Disonível em:

https://www.denatran.gov.br/download/Resolucoes/RESOLUCAO_CONTRAN_396_11.pdf. Acesso em: 27/05/2016

Caiado, R.G.G.; R. F. Dias, L.V. Mattos, O.L.G. Quelhas e W. Leal Filho (2017). Towards sustainable development through the perspective of eco-efficiency - A systematic literature review. Journal of Cleaner Production v. 165, p. 890-904. DOI:10.1016/j.jclepro.2017.07.166

Carvalho, C. H. R. (2011). Emissões relativas de poluentes do transporte motorizado de passageiros nos grandes centros urbanos brasileiros. Instituto de Pesquisa Econômica Aplicada (IPEA) no 1606, Brasília. Disponível em: http://hdl.handle.net/10419/91332. (Acesso em: 27/05/2016)

Charnes, A.; W. Cooper e E. Rhodes (1978). Measuring the efficiency of decision-making units. European Journal of Operational Research, v. 2, n. 6, p. 429-444. DOI: 10.1016/0377-2217(78)90138-8

CONPET. Programa Nacional de Racionalização do uso dos derivados de petróleo e gás natural (2016) Programa Brasileiro de Etiquetagem Veicular (PBE) lança tabela com modelos de 2016. Disponível em:

$<$ http://pbeveicular.petrobras.com.br/TabelaConsumo.aspx.

http://www.inmetro.gov.br/consumidor/pbe/veiculos_leves_2016.pdf - p.32-34>. Acesso em: 27/05/2016.

Deng X.; Y. Hu, Y. Deng e S. Mahadevan. (2014). Supplier selection using AHP methodology extended by D numbers. Expert Systems with Applications v. 41, n.1, p. 156-167. DOI: 10.1016/j.eswa.2013.07.018

Dinmohammadi, A. e M. Shafiee (2017). Determination of the Most Suitable Technology Transfer Strategy for Wind Turbines Using an Integrated AHP-TOPSIS Decision Model. Energies, v. 10, n. 5, p. 642. DOI: 10.3390/en10050642

Dong, Y.; G. Zhang, W.C. Hong e Y. Xu. (2010). Consensus models for AHP group decision making under row geometric mean prioritization method. Decision Support Systems, v. 49, n. 3, p. 281-289. DOI: 10.1016/j.dss.2010.03.003

Diabat, A. R.; Khodaverdi R. e L. Olfat (2013). An exploration of green supply chain practices and performances in an automotive industry. The International Journal of Advanced Manufacturing Technology, v. 68, n. 1-4, p. 949-961. DOI: 10.1007/s00170-013-4955-4.

Dweiri, F; S. Kumar, S.A. Khan e V. Jain. (2016). Designing an integrated AHP based decision support system for supplier selection in automotive industry. Expert Systems with Applications, v. 62, p. 273-283. DOI: 10.1016/j.eswa.2016.06.030

Efe, B. (2016). An integrated fuzzy multi-criteria group decision-making approach for ERP system selection. Applied Soft Computing, v. 38, p. 106-117. DOI: 10.1016/j.asoc.2015.09.037

EPE. (2014). Plano Nacional de Energia 2050. Empresa de Pesquisa Energética. Disponível em: http://www.epe.gov.br/sitespt/publicacoes-dados-abertos/publicacoes/PublicacoesArquivos/publicacao-227/topico201/PNE2050_Premissas\%20econ\%C3\%B4micas\%20de\%20longo\%20prazo.pdf. Acesso em: 27/05/2016

Gomes, L. F. A. M.; M.C.G. Araya e C. Carignano (2004) Tomada de decisão em cenários complexos: introdução aos métodos discretos do apoio multicritério à decisão, Pioneira, Thompson Learning.

Gonzalez, E.D.; J. Sarkis; D. Huisingh; L. H. Huatuco; N. Maculan; J. Montoya e de Almeida, C. M. V. B. (2015). Making real progress toward more sustainable societies using decision support models and tools: Introduction to the special volume. Journal of Cleaner Production v. 105, p. 1-13. DOI:10.1016/j.jclepro.2015.05.047

Hwang, C.L e K. Yoon (1981). Multiple Attribute Decision Making Methods and Applications. Springer. Verlag, Berlin.

Hwang, C.L.; Y.J. Lai e T.Y. Liu. (1993). A new approach for multiple objective decision making. Computers \& Operations Research. v. 20, n. 8, p. 889-899. DOI: https://doi.org/10.1016/0305-0548(93)90109-V

Jain, V.; Sangaiah, A.K.; Sakhuja, S.; Thoduka, N. e Aggarwal, R. (2016) Supplier selection using fuzzy AHP and TOPSIS: a case study in the Indian automotive industry. Neural Computing and Applications, p. 1-10. DOI: 10.1007/s00521-016-2533-z

Karahalios, H. (2017). The application of the AHP-TOPSIS for evaluating ballast water treatment systems by ship operators. Transportation Research Part D: Transport and Environment, v. 52, parte A, p. 172-184. DOI: 10.1016/j.trd.2017.03.001

Kahraman, C. (Org.) (2008). Fuzzy multicriteria decision making: theory and applications with recent developments. Turkey: Springer Science.

Kim, S.; K. Lee, J.K. Cho e C.O. Kim (2011) Agent-based diffusion model for an automobile market with fuzzy TOPSIS-based product adoption process. Expert Systems with Applications. v. 38, n. 6, p. 7270-7276. DOI: 10.1016/j.eswa.2010.12.024

Krohling, R.A. e V.C. Campanharo. (2011). Fuzzy TOPSIS for group decision making: a case study for accidents with oil spill in the sea. Expert Systems with Applications, v. 38, n .4, p. 4190-4197. DOI: 10.1016/j.eswa.2010.09.081

Lima Junior, F. R. e L. C. R. Carpinetti. (2015) Uma comparação entre os métodos TOPSIS e Fuzzy-TOPSIS no apoio à tomada de decisão multicritério para seleção de fornecedores. Gestão e Produção, São Carlos, v. 22, n. 1, p. 17-34, DOI: 10.1590/0104$530 X 1190$.

Lolli, F.; A. Ishizaka e R. Gamberini (2014) New AHP-based approaches for multi-criteria inventory classification. International Journal of Production Economics, v. 156, p. 62-74. DOI: 10.1016/j.ijpe.2014.05.015

Maniatopoulos, P.; Andrews, J. e B. Shabani (2015) Towards a sustainable strategy for road transportation in Australia: The potential contribution of hydrogen. Renewable and Sustainable Energy Reviews, v. 52, p.24-34. DOI: 10.1016/j.rser.2015.07.088

Mobinizadeh, M.; P. Raeissi; A. Nasiripour, A. Olyaeemanesh e L.S.J. Tabibi (2016). A model for priority setting of health technology assessment: the experience of AHP-TOPSIS combination approach. DARU Journal of Pharmaceutical Sciences, v.24, n.10. DOI: 10.1186/s40199-016-0148-7 
Meyer, I. e S. Wessely (2009) Fuel efficiency of the Austrian passenger vehicle fleet — analysis of trends in the technological profile and related impacts on $\mathrm{CO} 2$ emissions. Energy Policy, v. 37.

Oberhofer, P. e M. Dieplinger, (2014). Sustainability in the Transport and Logistics Sector: Lacking Environmental Measures. Business Strategy and the Environment. v. 23, n. 4, p. 236-253. DOI: 10.1002/bse.1769

Olson, D. L. (2004). Comparison of Weights in TOPSIS Models. Mathematical and Computer Modelling, v. 40, n. 7-8, p.721-727. DOI: $10.1016 /$ j.mcm.2004.10.003

Pazdernik, K.; M. Ander; S. Göttlicher; D. Kother; S. Pouper; G. Stranner e M.A. Zechmeister (2010). Emssionstrends 19902008 - Ein Uberblick uber die Österreichischen Verursachervon Luftschadstoffen. Datenstand.

Philipon, P. (2010). O Futuro da Mobilidade: rumo a uma mobilidade rodoviária sustentável. Éditions Textuel.

Picazo-Tadeo, A.J.; M. Beltrán-Esteve e J.A. Gómez-Limón (2012). Assessing eco-efficiency with directional distance functions. European Journal of. Operational. Research, v. 220, n. 3, p.798-809. DOI: 10.1016/j.ejor.2012.02.025

Puthanpura, A.K.; R, Khalifa e L. Chan (2015). Assessing emerging automotive technologies for the future. Portland International Conference on Management of Engineering \& Technology. September, 2015, p. 2113-2120. DOI:10.1109/PICMET.2015.7273223

Rashidi, K. e R. Farzipoor Saen (2015). Measuring eco-efficiency based on green indicators and potentials in energy saving and undesirable output abatement. Energy Economics, v. 50, p.18-26. DOI: 10.1016/j.eneco.2015.04.018

Saaty, T. L. (1980). The analytic hierarchy process. New York: McGraw-Hill.

Sadeghzadeh, K. e M. B. Salehi (2011). Mathematical analysis of fuel cell strategic technologies development solutions in the automotive industry by the TOPSIS multi-criteria decision making method. International Journal of Hydrogen Energy, v. 36, n. 20, p. 13272-13280. DOI: 10.1016/j.ijhydene.2010.07.064

Salgado, E.G.; V.A.P. Salomon; C.H.P. Mello e R.M. Alvarenga (2011). Tomada de decisão em grupo na priorização de atividades de desenvolvimento de novos produtos em empresas médias de eletrônicos. XLIII SBPO - simpósio brasileiro de pesquisa operacional, Ubatuba-SP.

Simão, V.G. (2011). Fatores estruturantes para implantação do programa brasileiro de avaliação do ciclo de vida. Dissertação apresentada ao curso de Mestrado em Sistemas de Gestão da Universidade Federal Fluminense. Área de concentração: Gestão Ambiental, p.133

Sindhu, S.; V. Nehra, e S. Luthra (2017). Investigation of feasibility study of solar farms deployment using hybrid AHP-TOPSIS analysis: Case study of India. Renewable and Sustainable Energy Reviews, v. 73, p. 496-511. DOI: 10.1016/j.rser.2017.01.135

Tyagi, M.; P. Kumar e D. Kumar (2014). A hybrid approach using AHP-TOPSIS for analyzing e-SCM performance. Procedia Engineering, v. 97, p. 2195-2203. DOI: 10.1016/j.proeng.2014.12.463

Tomashevskii, I.L. (2014) Geometric mean method for judgement matrices: formulas for errors. Institute of Mathematics, Information and Space Technologies, Northern (Arctic) Federal University, Arkhangelsk 163000, Russia.

Vaidya, O.S. e S. Kumar (2006) Analytic hierarchy process: An overview of applications. European Journal of Operational Research, v. 169, n. 1, p.1-29. DOI: 10.1016/j.ejor.2004.04.028

Vinodh, S.; T.S. Sai Balagi e A. Patil (2016). A hybrid MCDM approach for agile concept selection using fuzzy DEMATEL, fuzzy ANP and fuzzy TOPSIS. The International Journal of Advanced Manufacturing Technology, v. 83,n. 9-12, p. 1979-1987. DOI: 10.1007/s00170-015-7718-6

Xie, X.; Q. Zhu e Z. Chang (2013). Performance Evaluation of Automobile ASPs Using TOPSIS. 2013 Fourth International Conference on Digital Manufacturing and Automation, p. 910-913. DOI:10.1109/ICDMA.2013.214

Yang, S.S.; N. Nasr, S.K. Ong e A.Y.C. Nee (2015). Designing automotive products for remanufacturing from material selection perspective. Journal of Cleaner Production. v. 53, p. 570-579. DOI: 10.1016/j.jclepro.2015.08.121

Yildirim, V.; T. Yomralioglu; R. Nisanci; H.E. Çolak; S. Bediroglu, e E. Saralioglu (2016). A spatial multicriteria decision-making method for natural gas transmission pipeline routing. Structure and Infrastructure Engineering, v. 13, n. 5, p. 1-14 DOI: 10.1080/15732479.2016.1173071.

Yousefi, A. e A. Hadi-Vencheh (2010). An integrated group decision making model and its evaluation by DEA for automobile industry. Expert Systems with Applications, v. 37, n. 12, p. 8543-8556. DOI:10.1016/j.eswa.2010.05.021

Zhang, W. (2015) Group-Buying Websites Evaluation Model Based on AHP-TOPSIS under the Environment of Multi-Attribute Decision-Making. International Journal of Multimedia and Ubiquitous Engineering, v. 10, n.7, p. 31-40. DOI:10.14257/ijmue.2015.10.7.04

Zhou, G.; W. Chung e Y. Zhang (2014). Measuring energy efficiency performance of China's transport sector: a data envelopment analysis approach. Expert Systems with Applications, v. 41, n.2, p. 709-722. DOI: 10.1016/j.eswa.2013.07.095

Ziolkowska J. R. e B. Ziolkowski (2015). Energy efficiency in the transport sector in the EU-27: A dynamic dematerialization analysis. Energy Economics, v. 51, p. 21-30. DOI: 10.1016/j.eneco.2015.06.012 